${ }^{1}$ Sociedad Científica de

Estudiantes de Medicina los Andes (SOCIEMLA). Universidad Peruana los Andes (UPLA), Huancayo, Perú.

${ }^{2}$ Sociedad Científica de Estudiantes de Medicina de la Universidad Privada San Juan Bautista (SOCIEM UPSJB); Universidad Privada San Juan Bautista. Lima, Perú.

${ }^{3}$ Instituto de Investigación de Interculturalidad, Universidad Privada San Juan Bautista, Perú.
Corresponding author: Aquino Canchari Christian Renzo CC.HH Juan Parra del Riego II Etapa, Block 2, Dpto: 101, El Tambo, Huancayo, Peru Email address: christian aquino. canchari@gmail.com Phone: 051 - 934824051

Received: March 08, 2020 Accepted: September 08, 2020

\section{Body mass index and dental caries in native Peruvian communities}

\author{
Christian Renzo Aquino-Canchari ${ }^{1 *}$ (D), Diego Andre \\ Crisol-Deza ${ }^{2,3}$ (D), Joselyn Linda Zurita-Borja ${ }^{2,3}$ (D)
}

Oral disorders and eating disorders affect everyone, however, these will be more frequent in vulnerable populations such as native communities. Aim: Determining the body mass index and the prevalence of dental caries and its clinical consequences in native Peruvian communities. Methods: Observational, correlational, cross-sectional study. The sample consisted of 169 adults from the native communities selected for convenience, meeting inclusion and exclusion criteria. Nutritional status was evaluated through the body mass index, to quantify the experience of dental caries, the DMTF index was used, the severity was quantified by the significance index of dental caries, and its clinical consequences when not being treated by the PUFA index. The evaluation was carried out in natural light by calibrated observers. The data were analyzed in the STATA $v 14$ program using frequency distribution tables and figures, to determine the association, the Pearson's correlation coefficient was used. Results: The majority of residents had an adequate weight for their height 71 (41.01\%), followed by low weight 64 (37.87\%), overweight 29 (17.16\%) and obesity $5(2.96 \%)$. The prevalence of dental caries was $100 \%$ (DMTF = 13.23; SIC = 19.01), of which $68.04 \%$ had clinical consequences, no association was found between: BMI and DMTF ( $p=0.557) \mathrm{BMI}$ and PUFA-index (0.485). Conclusions: No association was found between the body mass index and dental caries and its clinical consequences.

Keywords: Nutritional status. Oral health. Population groups. Epidemiology. Dental caries. Peru. 


\section{Introduction}

Indigenous communities are culturally different societies and communities, presenting diverse religions, traditions, languages and histories, being a vulnerable population, in addition, it represents around $5 \%$ of the world population, of which $15 \%$ live in poverty ${ }^{1,2}$; in addition to having the worst health indicators compared to urban populations ${ }^{3}$. These inequalities and inequities may stem from globalization, poverty and marginalization, as well as barriers to accessing medical care ${ }^{4}$.

The diverse native communities constitute a high percentage of the population with food insecurity. Malnutrition, overweight or obesity has increased in this type of population, which can be related to the high consumption of carbohydrates, especially those in the form of sugars, increasing the risk of developing dental caries, this is caused by limited access to quality food, or due to the unavailability of rural stores where healthy products are sold ${ }^{5,6}$. In Peru, the fight against malnutrition, anemia and obesity has improved, but there is still a large gap ${ }^{7}$.

Decades ago it was recognized worldwide that oral diseases are a public health problem, the most frequent being dental caries. Peru is no stranger to this reality, according to the Peruvian Ministry of Health (MINSA) $90.4 \%$ of Peruvians have dental caries and $85 \%$ suffer from periodontal diseases ${ }^{8,9}$, being this reality more frequent and acute in vulnerable populations such as indigenous communities ${ }^{10}$.

The present study was carried out in the Ashanincas indigenous communities of Potsoteni, Union Puerto Ashaninca and Boca Sanibeni, located in the Ene River basin, belonging to the Mazamari district, Satipo province; Junin department, Peru, its economy is based on agriculture, hunting and fishing. Its main access routes are river and road transport ${ }^{11}$.

The objective of the present study was to determine the body mass index and dental caries in Peruvian indigenous communities.

\section{Materials and methods}

Observational, correlational, cross-sectional study. The sample was made up of 169 residents of both sexes, selected for convenience, who attended the dental care module installed in each community during the days of intervention (04/08/2018 to 08/11/2020), in the XII Camp Multidisciplinary University of Research and Service (CUMIS) of the Peruvian Student Medical Scientific Society (SOCIMEP), organized by the Scientific Society of Medical Students of the Center (SOCIEMC), belonging to the indigenous communities of Potsoteni, Boca Sanibeni and Union Puerto Ashaninka of Mazamari district, Satipo province, Junin department, Peru, the inclusion criteria were: belonging to the selected indigenous communities, over 18 years of age, signing the informed consent, the exclusion criteria were: presence of any impairment (physical, psychological or social).

For the evaluation of nutritional status, the body mass index was used using the formula BMI = Weight $(\mathrm{kg}) /$ Height $^{2}\left(\mathrm{~m}^{2}\right)$. Adults were evaluated barefoot and with a minimum of clothing, a calibrated SECA brand scale was used. The weight was recorded in 
kilograms $(\mathrm{kg})$. To measure height, the adult stood up straight, barefoot on the height meter. Height was recorded in centimeters $(\mathrm{cm})$, down to the nearest 0.5 . Once the measurements were obtained, they were extrapolated to the anthropometric calculator, provided by the WHO Anthro Plus 1.0.4 software. BMI was classified as low weight (BMI <18.5), normal (BMI 18.5 - 24.9), overweight (BMI 25-30), and obese (BMI> 30) ${ }^{12}$.

The experience of dental caries was evaluated using the DMFT index (permanent decayed, lost and filled teeth) ${ }^{13}$, for the diagnosis of dental caries, explorers, oral mirrors, with natural light were used, fulfilling the biosecurity criteria. He inspected the occlusal, vestibular, palatal, lingual, mesial, and distal faces of all permanent teeth present except for the third molars. The presence of caries was diagnosed if there was a visible loss of continuity of the dental surface, without the characteristics of a developmental defect and in pits and fissures when the end of the explorer "hooked" under light pressure ${ }^{14}$, to the degree of severity the dental caries significance index (SIC) was used ${ }^{15}$. To determine the clinical consequences of untreated dental caries, the PUFA index was used, which quantifies the number of teeth with presence of pulp exposure $(P / p)$, ulceration of the oral mucosa due to root fragments $(U / U)$, fistula $(F / f)$ and abscess $(A / a)^{16}$.

The clinical examination procedure was standardized, the research team was divided into three pairs: the first consisting of an examiner and an annotator, the second focused on the evaluation of weight and height, and a third focused on the collection of demographic data of the natives. The evaluators were subjected to calibration and concordance tests, the results were subjected to the Cohen's Kappa index to establish the agreement between the observers, obtaining the value 0.87 ( $p<0.005)$. The evaluations were made in the local school, under natural light, adapting the resources according to ergonomics and biosafety. To avoid fatigue bias, breaks were taken every ten evaluations per pair.

In order to collect the information, we had the support of bilingual translators from the community, who knew the research and the meaning of the questions to adapt the terms at the time of translation. After the inspection, each participant was given a hygiene kit consisting of a face soap, brush and toothpaste.

This study complies with the ethical principles of the Declaration of Helsinki, has the approval of the research ethics committee of the National Child Teaching Hospital San Bartolome, and the patients were previously consulted about their willingness to participate in the research by signing informed consent, explained what it consisted of and the possible benefit it would bring them. The project had the approval of the chiefs and residents of the selected native communities.

The data was analyzed in the Microsoft Excel 2016 program and subsequently statistical quantification was performed using the STATA v.14.0 statistical package, for descriptive analysis, percentages and frequency measurements, mean scores and standard deviations of the variables were obtained. The Pearson's correlation coefficient was used to determine the association.

\section{Results}

The sample was made up of 169 adults, the mean age was $29.13 \pm 11.05$ years, it was grouped by age group according to MINSA: young adult (18-29 years), adult 
(30-59 years) and adult older (60 years and older). The distribution of the selected sample was 99 women (58.57\%) and 70 men (41.43\%). (Table 1)

Table 1. Sample characteristics, by community, age group and sex.

\begin{tabular}{lccccccccc}
\hline & \multicolumn{3}{c}{ Indigenous communities } & \multicolumn{2}{c}{ Sex } & \multirow{2}{*}{ Total } \\
\cline { 2 - 8 } Age group & Potsoteni & $\begin{array}{c}\text { Boca } \\
\text { Sanibeni }\end{array}$ & $\begin{array}{c}\text { Unión } \\
\text { Puerto } \\
\text { Ashaninka }\end{array}$ & Male & & Female & & \\
\cline { 2 - 9 } & $\mathbf{n}(\%)$ & $\mathbf{n}(\%)$ & $\mathbf{n}(\%)$ & $\mathbf{n}$ & $\%$ & $\mathbf{n}$ & $\%$ & $\mathbf{n}$ & $\%$ \\
\hline Young adult & $31(18.34 \%)$ & $30(17.75 \%)$ & $43(25.44 \%)$ & 36 & $21.30 \%$ & 68 & $40.24 \%$ & 104 & $61.54 \%$ \\
\hline Adult & $24(14.20 \%)$ & $20(11.85 \%)$ & $19(11.24 \%)$ & 33 & $19.53 \%$ & 30 & $17.75 \%$ & 63 & $37 ; 27 \%$ \\
\hline Elderly & 0 & $1(0.59 \%)$ & $1(0.59 \%)$ & 1 & $0.61 \%$ & 1 & $0.61 \%$ & 2 & $1.19 \%$ \\
\hline Total & $55(32.54 \%)$ & $51(30.19 \%)$ & $63(37.27 \%)$ & 70 & $41.44 \%$ & 99 & $58.6 \%$ & 169 & $100 \%$ \\
\hline
\end{tabular}

Regarding the nutritional status of the native population, it was found that the majority presented an adequate weight for their height 71 (41.01\%), low weight 64 (37.87\%), overweight $29(17.16 \%)$ and obesity 5 (2.96\%). It should be noted that the female sex presented more cases of overweight and obesity. (Table 2)

Table 2. Body mass index of the inhabitants of native communities, according to sex.

\begin{tabular}{|c|c|c|c|c|c|c|}
\hline \multirow{3}{*}{ BMI } & \multicolumn{4}{|c|}{ Sex } & \multirow{2}{*}{\multicolumn{2}{|c|}{ Total }} \\
\hline & \multicolumn{2}{|c|}{ Male } & \multicolumn{2}{|c|}{ Female } & & \\
\hline & $\mathrm{n}$ & $\%$ & $\mathrm{n}$ & $\%$ & $\mathrm{n}$ & $\%$ \\
\hline Underweight & 27 & 15.98 & 37 & 21.89 & 64 & 37.87 \\
\hline Normal weight & 34 & 20.12 & 37 & 21.89 & 71 & 42.01 \\
\hline Overweight & 9 & 5.33 & 20 & 11.83 & 29 & 17.16 \\
\hline Obese & 0 & 0 & 5 & 2.96 & 5 & 2.96 \\
\hline
\end{tabular}

Regarding the prevalence of dental caries, this was 100\%, a population DMFT of 13.23 (4.91) was found, being slightly higher in the female sex, and with a severity of dental caries of 19.01, according to the group age. (Table 3)

Table 3. Prevalence, experience and significance of dental caries of the inhabitants of native communities, according to age group.

\begin{tabular}{lcccccc}
\hline & Prevalence & $\mathrm{C} \bar{x}(\mathrm{SD})$ & $\mathrm{P} \bar{x}(\mathrm{SD})$ & $\mathrm{O} \bar{x}(\mathrm{SD})$ & $\mathrm{CPOD} \bar{x}(\mathrm{SD})$ & $\mathrm{SIC}$ \\
\hline Age group & & & & & \\
\hline Young adult & $104(100)$ & $10.47(2.83)$ & $1.10(1.46)$ & $0(0)$ & $11.56(2.63)$ & 14.02 \\
\hline Adult & $63(100)$ & $13.87(5.06)$ & $2.05(2.49)$ & $0(0)$ & $15.34(4.69)$ & 16.66 \\
\hline
\end{tabular}

Continue... 
Continuation

\begin{tabular}{|c|c|c|c|c|c|c|}
\hline & Prevalence & $C \bar{x}(\mathrm{SD})$ & $\mathrm{P} \bar{x}(\mathrm{SD})$ & $O \bar{x}(S D)$ & CPOD $\bar{x}(S D)$ & SIC \\
\hline Elderly & $2(100)$ & $15(1.41)$ & $0(0)$ & $0(0)$ & 15 (1.15) & $0(0)$ \\
\hline Total & $169(100)$ & $11.79(4.15)$ & $1.44(1.96)$ & $0(0)$ & $13.23(4.91)$ & 15.34 \\
\hline \multicolumn{7}{|l|}{ Sexo } \\
\hline Male & 70 (100) & $11.21(3.96)$ & $1.14(1.58)$ & $0(0)$ & $12.36(4.49)$ & 15.65 \\
\hline Female & 99 (100) & $12.20(4.25)$ & $1.65(2.17)$ & $0(0)$ & $13.85(5.13)$ & 16.81 \\
\hline Total & $169(100)$ & $3.77(4.56)$ & 0.99 (1.32) & $0(0)$ & $13.23(4.91)$ & 16.23 \\
\hline
\end{tabular}

In relation to the prevalence of the clinical consequences of untreated dental caries, 115 (68.04\%) were residents, with the $\mathrm{P}$ component (pulp involvement) being the most frequent 112 (66.27\%). (Table 4)

Table 4. Frequency of components of the PUFA index of the inhabitants of native communities, according to age group and sex.

\begin{tabular}{|c|c|c|c|c|c|c|c|c|c|c|}
\hline & \multicolumn{8}{|c|}{ Index of clinical consequences of untreated tooth decay } & \multirow{2}{*}{\multicolumn{2}{|c|}{ Prevalence }} \\
\hline & \multicolumn{2}{|c|}{$\mathbf{P}$} & \multicolumn{2}{|c|}{$\mathbf{U}$} & \multicolumn{2}{|c|}{$\mathrm{F}$} & \multicolumn{2}{|c|}{ A } & & \\
\hline & $\mathrm{n}$ & $\%$ & $\mathrm{n}$ & $\%$ & $\mathrm{n}$ & $\%$ & $\mathrm{n}$ & $\%$ & $\mathrm{n}$ & $\%$ \\
\hline \multicolumn{11}{|l|}{ Age group } \\
\hline Young adult & 59 & 56.70 & 5 & 4.80 & 0 & 0 & 9 & 8.70 & 62 & 59.62 \\
\hline Adul & 51 & 81.10 & 16 & 25.4 & 3 & 4.80 & 9 & 14.3 & 51 & 80.95 \\
\hline Elderly & 2 & 100.0 & 0 & 0 & 1 & 50.0 & 1 & 50.0 & 2 & 100.0 \\
\hline Total & 112 & 66.27 & 21 & 12.43 & 4 & 2.36 & 19 & 11.24 & 115 & 68.04 \\
\hline \multicolumn{11}{|l|}{ Sexo } \\
\hline Male & 45 & 64.30 & 8 & 11.40 & 0 & 0 & 5 & 7.10 & 47 & 67.14 \\
\hline Female & 67 & 67.70 & 13 & 13.10 & 4 & 4.40 & 14 & 14.10 & 68 & 68.68 \\
\hline Total & 112 & 66.27 & 21 & 12.43 & 4 & 2.36 & 19 & 11.24 & 115 & 68.04 \\
\hline
\end{tabular}

Regarding the Pearson's correlation analysis between the BMI and the experience of dental caries and its clinical consequences, a very low correlation was found. Furthermore, there was no statistically significant association $(p>0.05)$ between the variables studied. (Table 5)

Table 5. Correlation between BMI and caries experience and its clinical consequences when not treated.

\begin{tabular}{|c|c|c|c|c|}
\hline \multirow{3}{*}{ BMI } & \multicolumn{2}{|c|}{ DMTF } & \multicolumn{2}{|c|}{ PUFA index } \\
\hline & rho & $p$ & rho & $p$ \\
\hline & 0.039 & 0.616 & 0.069 & 0.370 \\
\hline
\end{tabular}

Pearson Correlation (significance $\mathrm{p}<0.05$ ) 


\section{Discussion}

Nutritional disorders such as low weight, overweight and obesity are of growing concern not only in developed countries, but also in low-income countries such as Peru ${ }^{17}$. Our study found that most of the inhabitants had an adequate body mass index, in agreement with what was reported by De Souza-Filho et al. ${ }^{18}$ [BMI (mean = 26.65)] in Mura indigenous people of the Amazon region of Brazil, Romero et al. ${ }^{19}$ [BMI (mean $\left.\left.=24.20\right)\right]$ in residents of five native Ashaninka Peruvian communities and with Davison et al. ${ }^{20}$ [BMI (mean = 21.70)] in young indigenous adults from the north from Australia ${ }^{21}$. However, our study evidenced that a large number of underweight and overweight residents coexist, known as the "double burden of malnutrition", this is particularly noticeable in low-income countries such as Peru, this can manifest itself within a community, in the home or even in the same individual. According to the Food and Agriculture Organization of the United Nations (FAO), indigenous communities are at greater risk of food insecurity and malnutrition than other population groups ${ }^{22}$.

Another aspect to consider is that the majority of overweight and obese indigenous residents were female, in agreement with what was reported by Romero and others ${ }^{19}$, Boaretto and others ${ }^{23}$, this may be because women have a higher percentage of body fat, serotonin regulation, leptin levels, in addition to the progressive weight gain in pregnancy and menopause 24 .

Dental caries affects without distinction of social class, however, it affects more low-income people, our study showed a prevalence of 100\%, being higher than that reported by Soares and others $(91.6 \%)^{25}$ and Aamodt and others $(99 \%)^{26}$, in adult indigenous residents of Kaingang-Brazil and Chiapas-Mexico; respectively. In relation to the dental caries experience, our study found average scores lower than those reported in adult Guaraní indigenous settlers $(\text { DMTF }=13.9)^{27}$, Xavantes-Brasil $(\text { DMTF }=14.25)^{28}$ and from the Park. National Xingu-Brazil $(\mathrm{DMTF}=20.2)^{29}$ and higher than that reported by Jayashantah and Johnson (DMTF $=0.98$ ) in indigenous people of Sri Lanka ${ }^{30}$. In relation to the age group, older adults presented a higher average number of carious lesions compared to the rest, this could be explained by the fact that the enamel of the older adult undergoes natural wear ${ }^{31}$, in addition to the fact that many of them continue to accept that oral deterioration is normal and inevitable in old age.

Regarding the clinical consequences of untreated dental caries, the majority presented teeth with the presence of pulp exposure, the prevalence of PUFA was $68.04 \%$, being more frequent in the female sex, however, this is relatively high compared to infants ${ }^{32-34}$. Something important to mention is that no inhabitant had any dental restoration (amalgam and / or resin), this can be explained by the fact that the indigenous communities studied have a minor oral health service quality (limited to the topical application of fluoride), in addition, it is a challenge to have dental personnel who speak their indigenous language, which also compromises the quality of the service provided, this added to the distance from health institutions that have dental equipment ${ }^{35}$.

Our study found a very low correlation, and there was no statistically significant association between BMI and dental caries and its clinical consequences when not treated, 
being similar to what was reported by Adriano et al. ${ }^{36}$, in Mexican adults and contrary to what reported by Shestha and others in Nepalese teachers ${ }^{37}$,bthese discrepancies in the literature may be due to the multifactorial etiology of dental caries.

The change in the prevalence, experience of dental caries and its clinical consequences of not being treated and nutritional disorders in indigenous communities have increased mainly due to changes in diet, with the progressive inclusion of industrialized and sugar-rich products in their diet. In food, this can be explained by sociocultural, economic and environmental changes, as a result of their interaction with society ${ }^{38.39}$.

\section{Limitations:}

1. Variability that exists in the different ethnic groups existing in Peru, will not allow these results to be extrapolated to other countries in the region.

2. The cross-sectional design does not allow evaluating the causality of dental caries, and other variables such as food diet were not considered.

3. The sample size was not significant and the fact of evaluating the BMI values and not having considered other indicators to evaluate the nutritional status.

Our results show the need for the implementation of policies in oral health and food safety with an intercultural approach, both in prevention, as well as in the treatment of pathologies and their rehabilitation, guaranteeing accessible, quality care appropriate to the culture of these populations.

\section{References}

1. World Bank Group. Indigenous village. Washington, DC: World Bank; 2018 [cited 2020 Mar 1]. Available from: https://www.bancomundial.org/en/topic/indigenouspeoples.

2. World Bank Group. Indigenous Latin America in the Twenty-First Century. Washington, DC: World Bank; 2015. [cited 2020 Mar 1]. Available from: http://documents1.worldbank.org/curated/ en/145891467991974540/pdf/Indigenous-Latin-America-in-the-twenty-first-century-the-firstdecade.pdf.

3. Ghebreyesus TA. Improving the health of indigenous people globally. Lancet Oncol. 2018 Jun;19(6):e277. doi: 10.1016/S1470-2045(18)30375-9.

4. Sarfati D, Robson B, Garvey G, Goza T, Foliaki S, Millar E, et al. Improving the health of Indigenous people globally. Lancet Oncol. 2018 Jun;19(6):e276. doi: 10.1016/S1470-2045(18)30336-X.

5. Castro DB, Pinto RC, Albuquerque BC, Sadahiro M, Braga JU. The Socioeconomic Factors and the Indigenous Component of Tuberculosis in Amazonas. PLoS One. 2016 Jun;11(6):e0158574. doi: 10.1371/journal.pone.0158574.

6. Chyne DAL, Meshram II, Rajendran A, Kodali V, Getti N, Roy P, et al. Nutritional status, food insecurity, and biodiversity among the Khasi in Meghalaya, North-East India. Matern Child Nutr. 2017 Nov;13 Suppl 3(Suppl 3):e12557. doi: 10.1111/mcn.12557.

7. Rodríguez-Zúñiga MJ. [Obesity, overweight and anemia in children from a rural area of Lima, Peru]. Medicina (B Aires). 2015;75(6):379-83. Spanish.

8. Foley M, Akers HF. Does poverty cause dental caries? Aust Dent J. 2019 Mar;64(1):96-102. doi: 10.1111/adj.12666. 
9. Costa SM, Martins CC, Pinto MQC, Vasconcelos M, Abreu MHNG. Socioeconomic factors and caries in people between 19 and 60 years of age: an update of a systematic review and meta-analysis of observational studies. Int J Environ Res Public Health. 2018 Aug 18;15(8):1775. doi: 10.3390/ijerph15081775

10. Peruvian Ministry of Health. [90,4\% of Peruvians have tooth decay]. Lima, Peru.: MINSA; 2018 [cited 2020 Mar 1]. Available from: https://www.gob.pe/institucion/minsa/noticias/45475-el-904-de-los-peruanos-tiene-caries-dental. Spanish.

11. Regional Government Junin. [Diagnosis of health in children under 05 years old in 17 native communities and 33 annexes of the Ene River watershed]. [Internet]. Satipo, Peru; 2016 [cited 2020 Mar 1]. Available from: http://www.congreso.gob.pe/Docs/comisiones2017/ Comision_de_Pueblos_Andinos/files/sexta_sesi\%C3\%B3n_ord_17-10-2017/anexo_3..pdf. Spanish.

12. Ravasco P, Anderson H, Mardones F. [Methods of valuation of the nutritional condition]. Nutr Hosp. 2010;25(Suppl 3):57-66. Spanish.

13. World Health Organization. Oral health surveys: basic methods. 5th ed. Geneva; WHO; 2013 [cited 2020 Mar 1]. Available from: https://www.who.int/oral_health/publications/9789241548649/enrev.

14. Andrade Páez M, De la Cruz D. [Indicators of prevalence and prediction of dental caries risk]. VERTIENTES.2014 [cited 2020 Mar 1];17(1):61-72. Available from: https://www.medigraphic.com/ pdfs/vertientes/vre-2014/vre141g.pdf. Spanish.

15. Gonzáles V, Alegret M, Martínez J, Gonzáles Y. [Dental caries risk index]. Rev Cubana Estomatol. 2017; 54(1):34-47. Spanish.

16. Monse B, Heinrich-Weltzien R, Benzian H, Holmgren C, van Palenstein Helderman W. PUFA--an index of clinical consequences of untreated dental caries. Community Dent Oral Epidemiol. 2010 Feb;38(1):77-82. doi: 10.1111/j.1600-0528.2009.00514.x.

17. De la Cruz Sánchez EE. [The Nutrition Transition. Approach from Public Policy in Latin America]. Opción. 2016; 32(11):379-402. Spanish.

18. de Souza Filho ZA, Ferreira AA, Dos Santos J, Meira KC, Pierin AMG. Cardiovascular risk factors with an emphasis on hypertension in the Mura Indians from Amazonia. BMC Public Health. 2018 Nov 13;18(1):1251. doi: 10.1186/s12889-018-6160-8

19. Romero C, Zavaleta C, Cabrera L, Gilman RH, Miranda JJ. [High blood pressure and obesity in indigenous Ashaninkas of Junin region, Peru]. Rev Peru Med Exp Salud Publica. 2014;31(1):78-83. Spanish.

20. Davison B, Goodall J, Whalan S, Montgomery-Quin K, Howarth T, Singh G. Nutritional dual burden in Indigenous young adults: The geographical differential. Aust J Rural Health. 2019 Feb;27(1):14-21. doi: $10.1111 /$ ajr.12439.

21. Monteban M, Yucra Velasquez V, Yucra Velasquez B. Comparing Indigenous and public health infant feeding recommendations in Peru: opportunities for optimizing intercultural health policies. J Ethnobiol Ethnomed. 2018 Nov 20;14(1):69. doi: 10.1186/s13002-018-0271-2.

22. Arza Insfran EA, Collante Lavand V, Sanabria M, Acosta J, Morínigo Martínez M. [Double burden of malnutrition in mothers and children under five years of age in two indugenous communities of the Central Departament]. An Fac Cienc Med (Asunción). 2018;51(3):53-60. Spanish. doi: 10.18004/anales/2018.051(03)53-060.

23. Boaretto JD, Molena-Fernandes CA, Pimentel GG. [The nutritional status of Kaingang and Guarani indigenous peoples in the State of Paraná, Brazil]. Cien Saude Colet. 2015 Aug;20(8):2323-8. Portuguese. doi: 10.1590/1413-81232015208.14462014

24. Pizzi R, Fung L. [Obesity and woman]. Rev Obstet Ginecol Venez. 2015;75(4):221-4. Spanish.

25. Soares GH, Aragão AS, Frias AC, Werneck RI, Biazevic MGH, Michel-Crosato E. Epidemiological profile of caries and need for dental extraction in a Kaingang adult Indigenous population. Rev Bras Epidemiol. 2019 Aug 19;22:e190042. doi: 10.1590/1980-549720190042. 
26. Aamodt K, Reyna-Blanco O, Sosa R, Hsieh R, De la Garza Ramos M, Garcia Martinez M, et al. Prevalence of caries and malocclusion in an indigenous population in Chiapas, Mexico. Int Dent J. 2015 Oct;65(5):249-55. doi: 10.1111/idj.12177

27. Alves Filho P, Santos RV, Vettore MV. [Oral health of Guaraní Indians in the State of Rio de Janeiro, Brazil]. Cad Saude Publica. 2009 Jan;25(1):37-46. Portuguese. doi: 10.1590/s0102-311×2009000100004.

28. Arantes R, Santos RV, Coimbra CE Jr. [Oral health among the Xavánte Indians in Pimentel Barbosa, Mato Grosso, Brazil]. Cad Saude Publica. 2001 Mar-Apr;17(2):375-84. Portuguese. doi: 10.1590/s0102-311×2001000200012.

29. Hirooka LB, Mestriner-Junior W, Mestriner SF, Nunes SAC, Lemos PN, Franco LJ. Dental caries dental in mother-child couples of Xingu. Braz J Oral Sci [Internet]. 2014;13(1):43-6. doi: 10.1590/1677-3225v13n1a09.

30. Jayashantha P, Johnson NW. Oral Health Status of the Veddas--Sri Lankan Indigenous People. J Health Care Poor Underserved. 2016 Feb;27(1 Suppl):139-47. doi: 10.1353/hpu.2016.0039.

31. Chávez-Reátegui B, Manrique-Chávez J, Manrique-Guzmán J. [Geriatric dentistry and Gerodontology: Aging and oral characteristics of elderly patients. Review]. Rev Estomatol Herediana. 2014;24(3):199-207. Spanish.

32. Tsai C, Blinkhorn A, Irving M. Oral Health Programmes in Indigenous Communities Worldwide-Lessons learned from the field: A qualitative systematic review. Community Dent Oral Epidemiol. 2017 Oct;45(5):389-97. doi: 10.1111/cdoe.12302.

33. Carrasco-Loyola M, Orejuela-Ramirez F. [Clinical consequences of untreated dental caries in preschool and school children of public educational Institutions]. Rev Estomatol. Herediana. 2018;28(4):223-8. Spanish. doi: 10.20453/reh.v28i4.3425.

34. Rogers HJ, Tariq U, Olsson L, Riaz SA, Miah MR. Caries prevalence, clinical consequences and self-reported pain experienced by children living in the West Bank. Eur Arch Paediatr Dent. 2019 Aug;20(4):333-8. doi: 10.1007/s40368-018-00412-6.

35. Aliaga-Del Castillo A, Mattos-Vela MA, Aliaga-Del Castillo R, Del Castillo-Mendoza C. [Malocclusions in children and adolescents from villages and native communities in the Ucayali Amazon region in Peru]. Rev Peru Med Exp Salud Publica. 2011 Mar;28(1):87-91. Spanish. doi: 10.1590/s1726-46342011000100014.

36. Adriano-Anaya MP, Caudillo-Joya T, Caudillo-Adriano PA. [Dental Caries its Association with Body Mass Index in a Young Adult Population]. Int J Odontostomat. 2017;11(4):437-42. Apanish. doi: $10.4067 /$ S0718-381X2017000400437.

37. Shrestha S, Shrestha RM. Correlation Between Oral Health and Body Mass Index among Nepalese Teachers. Kathmandu Univ Med J (KUMJ). 2016 Jul-Sept.;14(55):231-4.

38. Restrepo-Arango M, Gutiérrez-Builes LA, Ríos-Osorio LA. Food security in indigenous and peasant populations: a systematic review. Cien Saude Colet. 2018 Apr;23(4):1169-81. doi: 10.1590/1413-81232018234.13882016. Retraction in: Cien Saude Colet. 2019 Jan;24(1):343.

39. Hita SR. [Health, globalization and interculturalism: an anthropological approach to the situation of indigenous peoples in South America]. Cien Saude Colet. 2014 Oct;19(10):4061-9. Spanish. doi: 10.1590/1413-812320141910.09372014. 